\title{
STRATEGIC INTEREST ANALYSIS FOR THE ORGANIZATION OF THE FUTURE
}

\author{
A.S. (Jim) Sethi \\ Business and Technology Department \\ University of Montana - Western
}

\begin{abstract}
The author analyzes the model of Strategic Interest Analysis (SIA) as a fundamental tool that leaders can profitably use in developing productive strategies relevant for the emerging organizations in the new millennium. The author explains the role of SLA in developing mission, philosophy, and strategic intent of an organization. He identifies internal as well as external challenges facing large organizations and the need for aligning vision and organizational culture in an emerging information economy. Guidelines in developing SIA and strategic vision skills are included, as well as critical skills needed for developing interest-based leadership.

Key Words: Interest-Based Leadership, Strategic Vision Analysis

\section{STRATEGIC INTEREST ANALYSIS FOR THE ORGANIZATION OF THE FUTURE}

"Strategic Interest Analysis" or SIA is a fundamental interest-based leadership strategy for promoting positive organizational empowerment and strategic success. SIA is a proactive process that can help clarify the linkage between an organization's core values and the stressors it faces with the ultimate objective of achieving better performance, improved quality of worklife, and a customer-driven viable, flexible, and competitively efficient world-class organization in the new global information economy.
\end{abstract}

\section{Emerging Interests In The Organization Of The Future}

Become aware of the changing role of leadership in analyzing the emerging interests of the organization of the future. Interest-based leaders will guide organizational

JOURNAL OF INTERNATIONAL BUSINESS AND ECONOMY Fall 2001
FIRST RECEIVED: DECEMTER 41999 FINAL REVISION ACCEPTED: MAY 262000 
transformation in accordance with the following principles relating to leadership interests (Cox and Rock 1997, 75):

1. Learn the new language of interest-based leadership, emphasizing inner change and spiritual development.

2. Be ready to lead the more flexible, but less hierarchical organization of the future.

3. Lead from the grass roots and learn to listen to the voice of the people.

4. Create organizations with many leaders.

5. Develop the art of archetypal learning. "People learn when they learn archetypally, when they can embrace images that capture their passion and illuminate important lessons".

6. Align organizational culture to new leadership. Shape and keep a performanceoriented culture.

7. Be prepared to lead a diverse work force.

8. Turn your organizational pyramid upside down.

9. Understand and use the power of partnering in becoming a world-class leader in meeting future global challenges.

10. Ask, envision, learn, follow-up, and grow.

11. Develop a service-oriented ethic in your leadership style.

The future environment of global organizational life is becoming increasingly differentiated and complex and results in a variety of multiple stressors in the environment. ${ }^{2}$ The new era will reflect an increasing trend toward decentralization, borderless, transnational corporations, and increasingly democratic structures emphasizing employee involvement, empowerment and strategic change. As 'win-win' leaders, you can use SIA as a tool for analyzing the environment and its opportunities in light of emerging organizational and societal values.

\section{Phases of SIA}

SIA involves eight key phases that are outlined in Figure 1. These phases may be taken cybernetically, i.e., you may move backward and forward to refine each phase.

- Identify core values in your organization's mission statement.

- Identify internal challenges and unique organizational characteristics.

- Identify challenges from the external environment and their impacts, both locally and globally.

- Examine long-term objectives and their relation to challenges and your organization's score values. 
- Develop long-term grand strategies for managing challenges.

- Examine annual objectives and their relation to challenges and core values.

- Develop appropriate operating strategies to manage stressors.

- $\quad$ Share operating strategies with various teams.

- Implement your value strategy.

- Evaluate the effectiveness of selected strategies in understanding your organization's mission, its philosophy, and its core values.

Figure 1. Key Phases in Strategic Interest Analysis

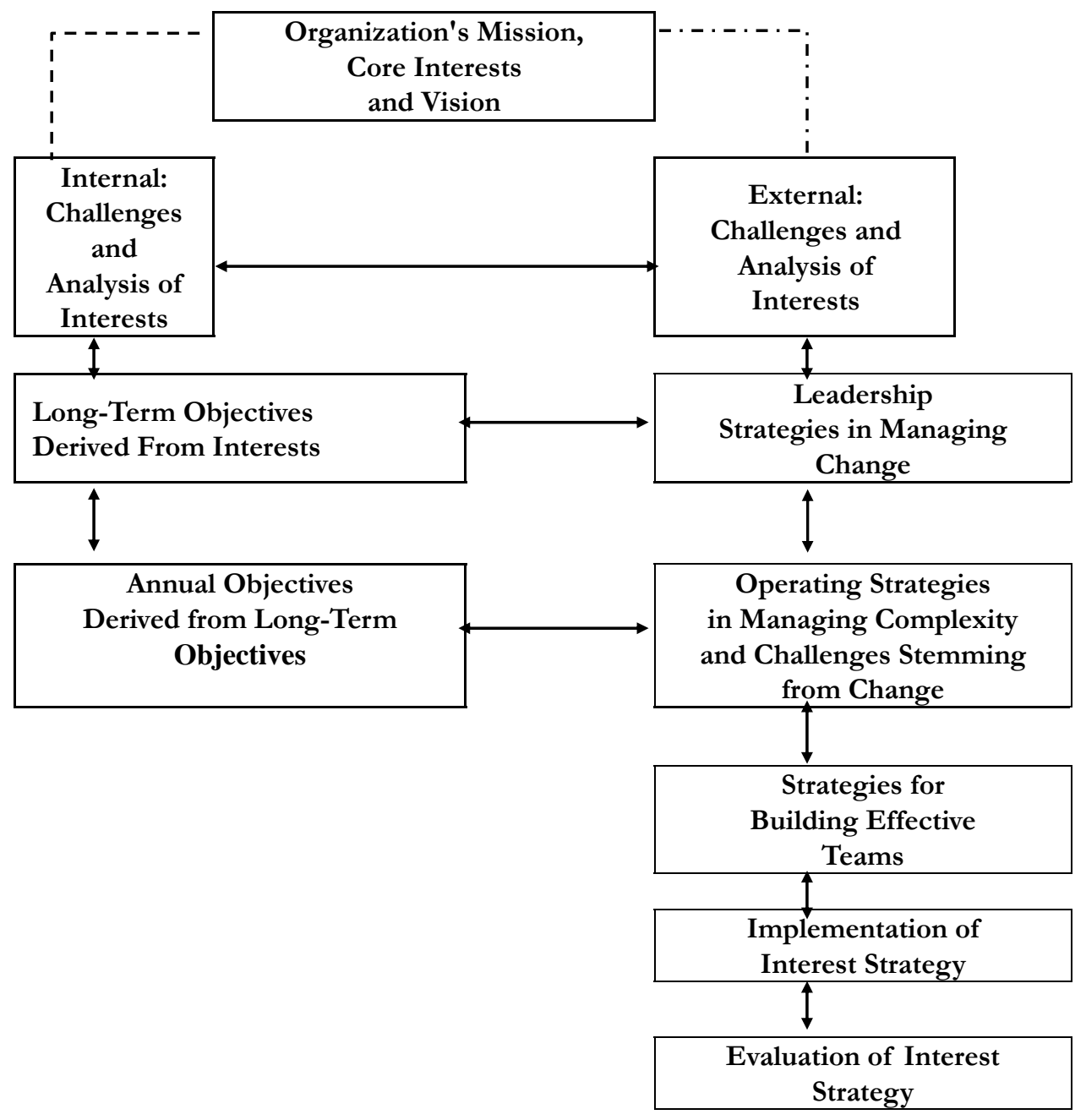




\section{Mission, Philosophy AND STRATEgIC INTENT}

The first phase in an organizational SIA begins with a commonly shared organizational philosophy and mission. An organization's mission is the fundamental, unique purpose that sets it apart from other organizations of its type and identifies the size of its operation in product, service and market terms. The mission is a general, enduring statement of an organization's core interests. It embodies the business philosophy of strategic decision-makers, and implies the "firm's ultimate aims. It projects a sense of worth and intent that can be identified and assimilated by outside stakeholders; that is, customers, suppliers, competitors, local committees, and the general public. Finally, it asserts the firm's commitment to responsible action in symbiosis with the preservation and protection of the essential claims of insider stakeholders' survival, growth, and profitability." (Hesselbein, Goldsmith, and Beckhard 1996)

Interests serve as the foundation on which is structured the organization's mission, which, in turn, influences the determination of long-term and short-term objectives, and of an implementation plan comprising functional procedures and strategies.

In order to make your organization interest-oriented, a well-thought-out creative vision is necessary. You need to develop a conscious map to implement the plan in a learning mode so that you can evaluate your interest path and the spirit of your mission. Normally, interest change is measured only in terms of results; rarely is there any measurement of the process of interest-creation and sharing of values. To become an interest-based leader, you need to chart your interest path, which endorses enthusiasm [visioning], direction [mapping], discovery [journeying], transformation [learning], sharing [mentoring], service [leading], and developing a spirit of community [valuing]. (Pearce and Robinson 1994, 52-53)

There are four key leadership actions that you can take to create and develop mission-oriented interests:

- Create and set the interests that clarify the organization's vision.

- Communicate and share these interests.

- Build commitment to interests.

- Inspire people in performance patterns that are aligned with these interests.

\section{Identity Internal Challenges and Analyze Organizational}

\section{Characteristics}

An organization can identify its challenges by examining its profile in terms of organizational characteristics, particularly in reference to its strategic competencies and weaknesses. This can be accomplished by answering some key questions. What 
are the organization's unique characteristics? What are its strategic challenges? Where do they originate? How do we decide which challenges are positive (i.e., provide challenge and opportunity) in comparison to those which are perceived as negative (i.e., constraints and threats)?

Challenges can be identified by analyzing key organizational interest areas (Beckhard and Pritchard 1992):

(A) Organization's planning and marketing;

(B) Ways of work: production /operation/technical processes;

(C) Key relationships;

(D) Financial health and cost effectiveness; and

(E) Organizational culture.

Figure 2 gives examples of possible stressors in each of these areas that will result from rapid and fundamental change in the 21st century. Leaders need to think about the five key themes listed above and analyze them in relation to various internal challenges and stressors. Specifically, the focus of fundamental interest orientation should incorporate the following guidelines:

\section{Identity, Planning and Marketing}

- Clarify the organization's identity (as per its mission), or "reason to be", and identify opportunities, strengths, and areas needing improvement to cope proactively with perceived challenges and stressors in this area.

\section{Figure 2. Key Organizational Complexities and Stressors Stemming from} Fundamental Environmental Change

\section{IDENTITY, PlanNING AND MARKETING}

- A change in mission and lack of clear identity

- Planning too rationally

- Inadequate environmental scanning and analysis

- Low analysis of strategic choices in relation to key stressors

- Undefined breadth of product line: Range of services too demanding

- Concentration of sales or services to too few customers or clients

- Lack of ability to gather needed information about markets

- Inadequate market share

- Profit/sales imbalance

- Fragmented channels of distribution: number, coverage, and control

- Poor product/service image, reputation, and quality

- Ineffective sales organization; inadequate knowledge of customer/client needs

- Unimaginative, inefficient, and ineffective sales promotion and advertising

- Ineffective and rigid pricing strategy 
- Lack of procedures for digesting market feedback in developing new products, services or markets

- Lack of procedures for after-sales service and follow-up

- Lack of integration between corporate strategy and global competitiveness

- Lack of integration between offline and online business models

\section{Ways of Work and Production/Operation/TeChNiCAL Process}

- Inadequate attention to globalization

- Raw materials cost and availability, supplier relationships

- Inadequate inventory control systems and improper use of information technology

- Unsuitable layout and less than optimum utilization of facilities

- Failure to utilize economies of scale

- Technical inefficiency of facilities and of utilization of facilities

- Ineffective use of subcontracting

- Ineffective operations procedures: design, scheduling, purchasing, quality control, and efficiency

- Lack of focus and flexibility in research and development/technology/innovation

- Inappropriate policies on patents, trade names, and similar legal protection

- Lack of process innovation and its management

- Lack of customer-driven orientation

- Imbalance between technology-driven and customer-driven changes

- Lack of flexible strategic management

\section{KEY RELATIONSHIPS}

- Incongruent skills and attitudes that are not conducive to organization's values

- Low employee morale

- Too-high labor relations costs compared to industry and competition

- Poor collective bargaining: demands and process not well-managed

- Inadequate dispute resolution: alternatives and impacts based on tradition rather than creativity and collaboration

- Inequitable grievance procedure

- Inefficient and ineffective personnel policies

- Ineffective use of incentives to motivate performance

- Inability to level peaks and valleys of employment

- High employee turnover and absenteeism

- Failure to utilize specialized skills

- Effects of downsizing on organizational morale and competence

- Ineffective relationships amongst key stakeholders

- Demand for a reorientation of services and products caused by changes in public views and consumer habits 


\section{FINANCIAL HEALTH AND Cost EFFECTIVENESS}

- Less than ideal relations with owners, investors, and stockholders

- Inability to raise long-term capital: imbalanced debt/ equity

- Inability to raise short-term capital

- Inadequate corporate-level resources (multibusiness form)

- Cost of capital relative to industry and competitors

- Failure to include tax considerations in financial strategy

- Leverage position: inadequate capacity to utilize financial strategies, such as lease or sale and lease back

- Cost of entry and barriers to entry

- Imbalanced price-earning ratio

- Inadequate working capital; inflexibility of capital structure

- Ineffective cost control; pressures to reduce costs

- Inefficient and ineffective accounting systems and information for cost, budget, and project planning

- Emerging ethical dilemmas

\section{Ways of Work}

- Analyze the underlying values in the way work is organized and power is governed. Team leadership, process management, and customer-driven quality management are some of the values needed by global organizations. What are your opportunities, strengths, and areas needing improvement to cope proactively with perceived stressors in this area?

\section{Key Relationships}

- Analyze changes and accompanying stressors in relation to key stakeholders. Again, examine stressors related to human resource utilization and training in installing a customer-driven and quality improvement value process. What are your opportunities, strengths, and areas for improvement in developing positive relationships with key stakeholders, and building higher levels of synergy, commitment, and morale among your personnel?

\section{Financial Health and Cost Effectiveness}

- Analyze changes in the financial status of your organization and the extent to which strategic managers are able to acquire resources and develop cost-effective strategies, while keeping the organizational mission of image, quality and identity intact. Deal with the ethical dilemmas through which your organization may be undergoing a transitional change, confronting conflicts between efficiency and equity. What are your opportunities, strengths, and areas for improvement in this area? 


\section{Organizational Culture}

- Analyze changes in team culture and the types of stressors your organization is facing in a highly turbulent environment. Examine your role as a leader in communicating proactively those values that reinforce the type of culture you desire. In an era of strategic alliances and mergers, strategic value analysis is essential for coping with uncertainty and strains experienced by employees in a "reengineered" corporation. What are your opportunities, strengths, and areas for improvement in developing a new customer-oriented value set in a global environment?

\section{THE INTEREST IMPROVEMENT PROCESS}

As shown in Figure 3, there are three key phases in analyzing internal challenges, and improving the interest process:

Figure 3. Steps in the Analysis of Internal Complexity and Stressors: The Interest-Improvement Process

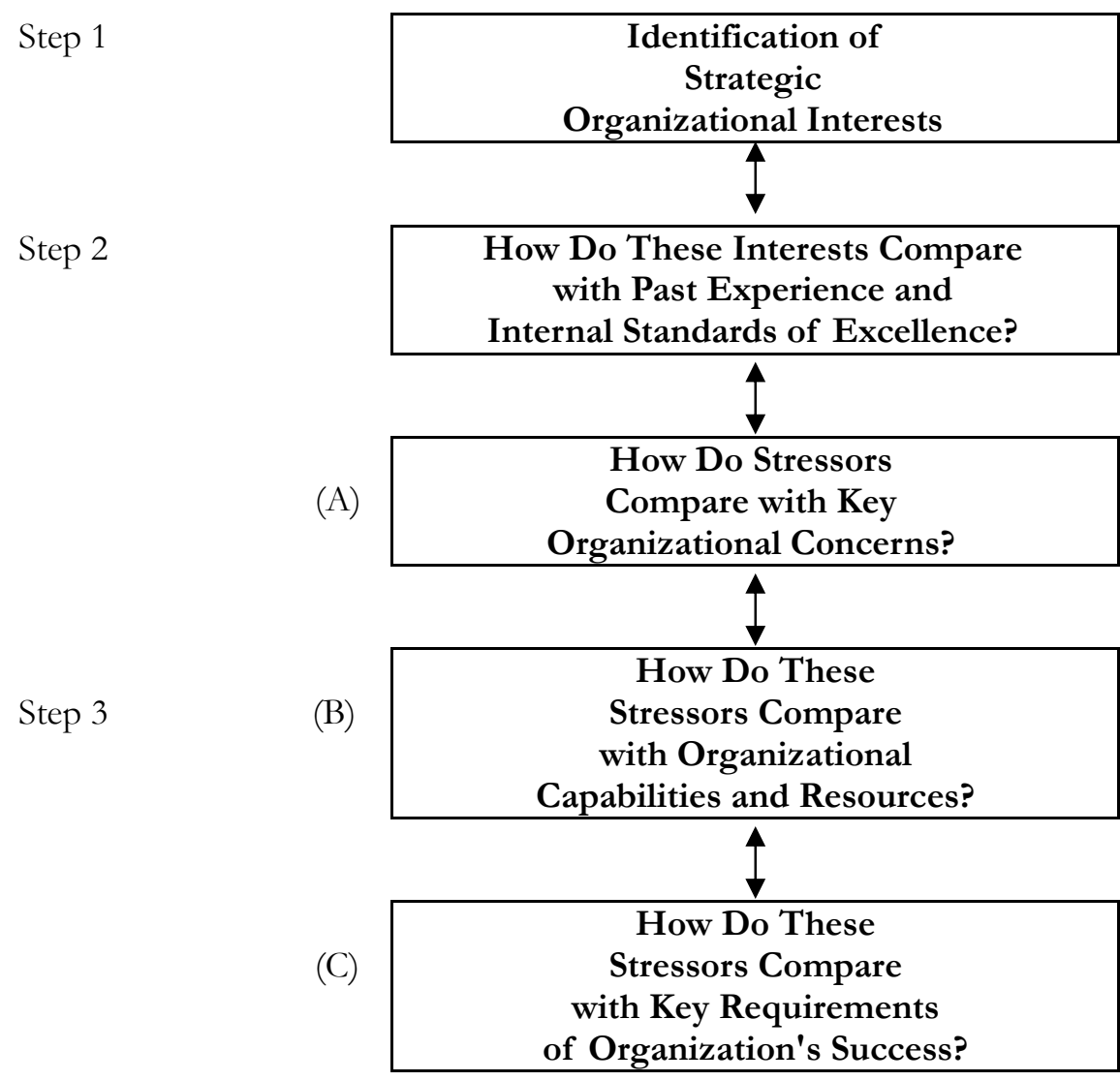




\section{In Phase 1:}

Identify basic core interests of the organization. Make sure that they reflect changes in mission, and are shared by various organizational teams and stakeholders.

\section{In Phase 2:}

Evaluate to what extent these interests have been incorporated in the recent past. Identify current and potential stressors in relation to each value factor. Does each value factor represent a positive or negative stressor?

\section{In Phase 3:}

Compare your success in coping with these stressors in relation to competition and internal capacity. Identify competitive advantages, basic business requirements, and key vulnerabilities in the areas of skills, knowledge or resources. These key vulnerabilities are areas that may generate future stressors, and provide feedback for introducing changes to your value-orientations and generating coping strategies for meeting with actual or potential stressors. This process of internal stressor analysis will then be matched with an analysis of external stressors arising from the external environment as explained in the next section.

\section{IDENTIFICATION OF EXTERNAL CHALLENGES}

At any given time, there are a number of external and often uncontrollable stressors that each organization must confront and incorporate into its strategic management process. In SVA, it is therefore essential to analyze stressors stemming from the broader or "remote environment" as well as the "operating or task environment".

Figure 4. Impacts of External Challenges on Organizational Interests and Team Environment

\begin{tabular}{c||c||c||c|c|}
\hline & $\begin{array}{c}\text { Organization } \\
\text { and its Core } \\
\text { Interest-system }\end{array}$ \\
$\begin{array}{c}\text { Complexity and } \\
\text { Challenges in the } \\
\text { Remote }\end{array}$ & $\begin{array}{c}\text { Stressors and } \\
\text { Their Impacts on } \\
\text { Core Interests }\end{array}$ & $\begin{array}{c}\text { Area of total } \\
\text { External } \\
\text { Environment: } \\
\text { Impacts on }\end{array}$ & $\begin{array}{c}\text { Source of } \\
\text { Impacts on Core } \\
\text { Interests }\end{array}$ \\
\hline \hline
\end{tabular}




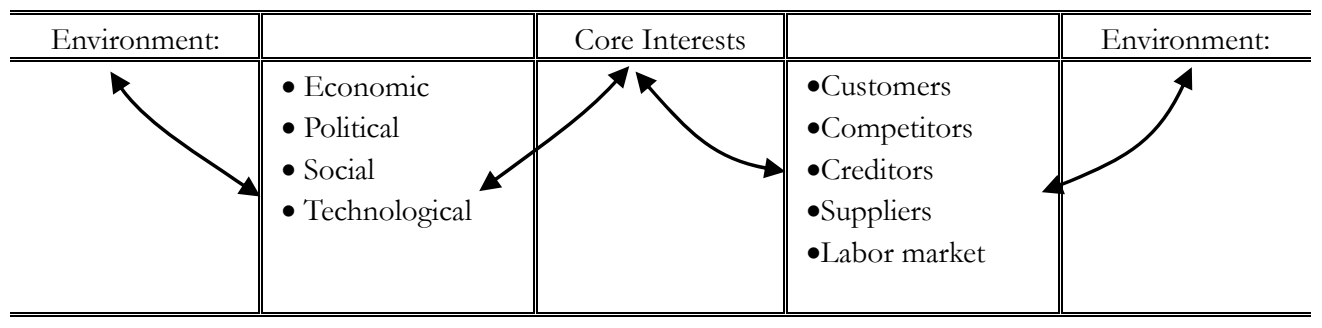

In order to trace stressors in the remote environment, you should examine various factors (such as political, economic, social and technological ones) as main sources of external stressors. The key sources of external stressors are changes in the economy, societal values and demographics, ecological values, technological imperatives, and global competitiveness, as well as new political realities.

The operating environment involves factors in the immediate competitive situation that provide many of the challenges a particular organization faces in attempting to attract or acquire needed resources or in striving to market its goods and services profitably. Factors that may generate stressors in the operating environment include an organization's competitive position, customer profile, reputation among suppliers and creditors, and accessible labor market. (Pearch and Robinson 2000)

Multinational global firms must evaluate their multiple interest set by examining several environments simultaneously. It is helpful to examine them in light of philosophy, public image, international regulations governing investments and trade, and diverse cultural factors. New values need to be introduced and incorporated in your organizational culture in order to meet with various external stressors stemming from both remote and operating environments.

\section{LONG-TERM OBBJECTIVES AND TEAM'S CORE INTERESTS}

Identify interests inherent in your organization by examining its long-term objectives. While its mission encompasses broad organizational interests (e.g. profitability, survival, and growth) and provides a general sense of direction, it is not intended to provide "specific benchmarks" for evaluating an organization's progress in achieving its aim. By analyzing long-term objectives, we can determine if the various teams are following the core interests depicted in the organization's mission statement.

Long-term objectives are statements of the results an organization seeks over a specified period of time, typically five years, in seven key interest areas. These include: profitability, productivity, competitive position, employee development, technology, and social responsibility. Examine each of these results in relation to various interests and stressors as shown in Table 1 "Strategic Interest Analysis through Long-Term 
Objectives". Throughout this chapter, interests and objectives have been used to convey a special meaning. Interests are ethical guide posts, whereas objectives translate those interests into action.

\section{ANNUAL OBJECTIVES AND INTERESTS IMPLEMENTATION}

Examine your organization's annual objectives and its functional strategies and policies. Annual objectives are time-bound targets to meet long-term objectives. They are powerful tools for strategy implementation. The key questions of relevance in SIA are:

Table1. Strategic Interest Analysis through Long-term Objectives

\begin{tabular}{|c|c|c|c|}
\hline $\begin{array}{l}\text { LONG-TERM } \\
\text { OBJECTIVES }\end{array}$ & MEASURE & $\begin{array}{l}\text { INTEREST } \\
\text { INDICATORS }\end{array}$ & $\begin{array}{c}\text { MAPPING THE SOURCE } \\
\text { OF STRATEGY } \\
\text { FORMATION } \\
\end{array}$ \\
\hline $\begin{array}{l}\text { STRATEGIC } \\
\text { MANAGEMENT, } \\
\text { PROFITABILITY }\end{array}$ & $\begin{array}{l}\text { - Earnings } \\
\text { per share } \\
\text { or return } \\
\text { on equity }\end{array}$ & $\begin{array}{l}\text { - Survival and global } \\
\text { growth via achieving } \\
\text { competitive edge }\end{array}$ & $\begin{array}{l}\text { - Political dynamics: micro } \\
\text { and macro power } \\
\text { - Technological changes } \\
\text { - Organizational changes } \\
\text { - Global economy and } \\
\text { access }\end{array}$ \\
\hline $\begin{array}{l}\text { TOTAL QUALITY } \\
\text { MANAGEMENT, } \\
\text { AND PROCESS } \\
\text { INNOVATION }\end{array}$ & $\begin{array}{l}\text { - Economies of } \\
\text { scales } \\
\text { - Business } \\
\text { systems } \\
\text { reengineering }\end{array}$ & $\begin{array}{l}\text { - Customer / client } \\
\text { satisfaction }\end{array}$ & $\begin{array}{l}\text { - Private-Public sector } \\
\text { partnership } \\
\text { - Technological change } \\
\text { - Mergers, strategic alliances } \\
\text { and joint ventures } \\
\text { - Equity concerns } \\
\text { - Human resource } \\
\text { management and labor } \\
\text { relations }\end{array}$ \\
\hline $\begin{array}{l}\text { COMPETITIVE } \\
\text { POSITION: } \\
\text { "MORE FROM } \\
\text { FEWER, } \\
\text { FASTER" }\end{array}$ & $\begin{array}{l}\text { - Global Market } \\
\text { share }\end{array}$ & $\begin{array}{l}\text { - Ethics of growth } \\
\text { and negotiated } \\
\text { strategies }\end{array}$ & $\begin{array}{l}\text { - Borderless economy } \\
\text { - Global competition }\end{array}$ \\
\hline $\begin{array}{l}\text { EMPLOYEE } \\
\text { DEVELOPMENT } \\
\text { AND LEARNING } \\
\text { ORGANIZATION }\end{array}$ & $\begin{array}{l}\text { - Diversity } \\
\text { management } \\
\text { - Skill } \\
\text { development } \\
\text { - Life } \\
\text { career planning }\end{array}$ & $\begin{array}{l}\text { - Internal social } \\
\text { dynamics } \\
\text { - Humanism: } \\
\text { employee } \\
\text { involvement }\end{array}$ & - Micro and macro culture \\
\hline INFORMATION & - Technological & - Technological & - De-skilling \\
\hline
\end{tabular}




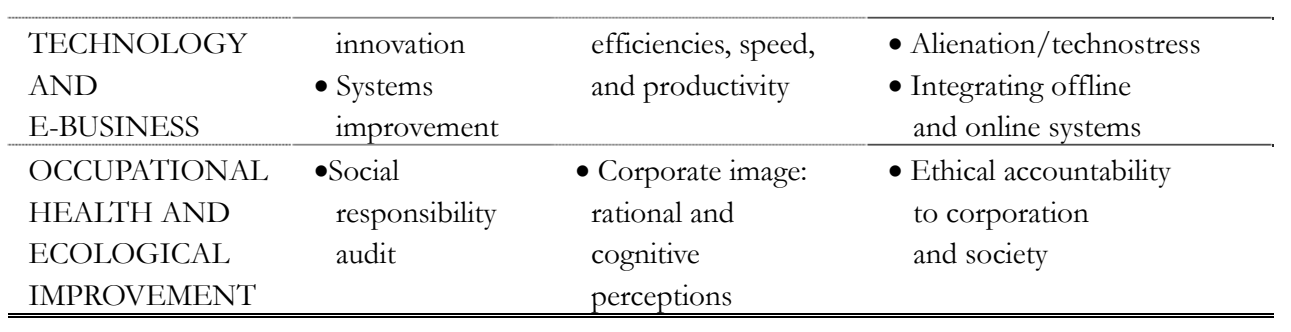

[Source: Based on ideas drawn from Pearce, J.A. \& Robinson, R.B. (1994), Strategic Management, Homewood, IL: Irwin, pp. 245-246, and Mintzberg, H. Ahlstrand, B, \& Lampel, J. (1998), Strategy Safari: A Guided Tour Through The Wilds of Strategic Management, New York: Free Press, pp. 350-373.]

- How effective are annual objectives in reflecting an organization's core interests?

- What are the stressors that stand as obstacles in implementing these objectives?

- Do these stressors stem from defective or incoherent objectives, or do they reflect inadequate functional strategies and policies?

Placed in this perspective, stressors can be diagnosed more accurately and the appropriate strategy-formation mechanism devised accordingly. Table 2 demonstrates the process of analyzing annual objectives in key areas, developing interest indicators, and selecting functional strategies to manage stressors proactively.

\section{Establish Interest-Related Priorities}

Another critical function of SIA is to ascertain if short-term objectives have been properly prioritized in light of an organization's interest system in the context of globalization change and long-term perspective. This function is necessary, due to relative competing resources. Many stressors stem from conflicts that arise out of competing objectives and resource allocation.

Systematic analysis of strategies and interests provides a meaningful focus and clarifies an organization's purpose as well as obstacles, demands and opportunities (stressors) encountered in meeting those objectives. This process can serve as a basis for providing effective team functioning, strategic control and evaluation.

\section{ACTION STRATEgIES}

Depending upon the aggregate "analysis of stressors and complexity" and interests, as suggested in interest improvement process, a number of interest-based leadership strategies are to be considered. In this IBL project I have proposed eight such strategies that can be used to proactively formulate strategy to deal with internal and external stressors in shaping and developing a world-class organization. "Strategy formation is judgmental designing, intuitive visioning, and emergent learning; it is 
about transformation as well as perpetuation; it must involve individual cognition and social interaction, cooperation as well as conflict; it has to include analyzing before and programming after as well as negotiating during; and all of this must be in response to what can be a demanding environment. Just try to leave any of this out and watch what happens!" (Mintzberg, Ahlstrand and Campbel 1998, 372)

\section{IMPLEMENTATION PLAN AND INTEREST CONGRUENCE}

In order to ensure effective implementation of your interests and leadership strategies, three questions should be answered:

1. Have you provided an adequate social structure for various parts and cross functional teams of the organization to implement leadership strategies?

2. Are there adequate resources?

3. Is leadership in the organization capable of and willing to learn in implementing these strategies?

\section{Evaluation, Control AND FEEDBACK}

Evaluate your organization's effectiveness in terms of efficiency, appropriateness, and overall effectiveness in achieving your organization's mission and core interests. Make appropriate changes based on your experience in SIA, by appraising and understanding the parts of the organization in order to appreciate the total system.

\section{BENEFITS OF STRATEgIC INTEREST ANALYSIS (SIA)}

There are a number of benefits from SIA:

1. SIA focuses on interests - "Where is the organization directed?" It thus helps to clarify mission, and provides a clear foundation for setting objectives and means for prioritizing core values.

2. SIA provides new insights as to why certain objectives are preferred in the organization and for whose benefit.

3. SIA helps organizations to cope with competition more effectively.

4. SIA helps to refine the ethical dimensions of an organization. It changes its role with regard to social responsibility in relation to its employees, clients or customers, and the general public.

\section{GUIDELINES IN DEVELOPING SIA}

- In order to carry out an effective assessment of challenges, opportunities, and stressors, you should ensure that adequate environmental data is collected. 
Perceptual data should be supplemented by objective data gathered from multiple sources. You should organize your data in such a way that it helps to give you facts and values as perceived by various stakeholders.

- You should undertake to convert data into relevant and meaningful information for determining the overall nature of stressors, to serve as a basis for formulating coping strategies.

- Be flexible in your approach in identifying stressors and complexities faced by various teams and how these are related to core organizational values. Your solutions should be designed, for example, to enhance quality process improvement, and customer-driven planning and marketing. Keep sharing your organizational philosophy with various team leaders.

- $\quad$ SIA is a long-term grand strategy. Therefore develop proactiveness, patience and sensitivity - needed leadership skills for conducting SIA.

- Place key emphasis on assessing the impact of stressors and complexity from the external environment, as they play a key role in determining the opportunities, threats, and constraints an organization faces. This requires knowledge and sensitivity to adapt to forces in the broader environment entailing economic, political, social and technological changes. It also helps the organization in adjusting its operating environment. The end result of this exercise is to provide better service to the organization's customers as well as to streamline its relations with suppliers and other stakeholders.

- Retain a sense of flexibility in your SIA framework in order to analyze various phases according to the unique parameters of each organization.

\section{INTEREST-BASED LEADERSHIP AND STRATEGIC VISION SKILLS}

Interest-based leaders of the future will need not only to develop the vision and directional interests of the organization but also to get involved in the implementation of strategy pertaining to the organization's shared vision and its interests. In other words, interest-based leadership is concerned with both effectiveness (vision and direction) and efficiency (implementation). As Blanchard has said, the leader of the future "has to manage the journey to effectiveness and efficiency to create an ultimate organization that knows where it is going and in which everyone is committed, organized, and ready to implement an agreed upon vision". (Blanchard 1996, 82-83)

\section{SEVEN SKILL-ASSESSMENT TIPS FOR INTERST-BASED LEADERS}

Despite the fact that future challenges to leadership are complex, interest-based leaders in the future can ensure survival and even grow and succeed. The following seven tips are valuable (Kouzes and Posner 1996): 
Tip \#1 Interest-based leaders are proactive.

Tip \#2 Interest-based leaders have credibility, clarity of interests, and integrity.

Tip \#3 Interest-based leaders foster teamwork and share values.

Tip \#4 Interest-based leaders have congruence. They mean what they say, and what they say, they will do.

Tip \#5 Interest-based leaders create value for their stakeholders. In a more complex, wired world, the winning strategies will generally be based upon the 'win-win' integrative philosophy.

Tip \#6 Interest-based leaders "have their head in the clouds and their feet on the ground. Not only do we demand that leaders be credible, we also demand that they be forward-looking: that they have a sense of direction and a vision for the future. This capacity to paint an uplifting and enabling picture of the future is, in fact, what differentiates leaders from other credible sources". (Kouzes and Posner 1996, 103)

Tip \#7 Anyone can become an interest-based leader, as leadership strategies and practices can be learned. Interest-based leadership is a 'win-win' strategy and is not confined to a few charismatic people, but is widespread in the organizational society. The ultimate tip is that "whether you are in the private sector or the public sector, whether you are on the front line or in the senior echelon, whether you are a student or a parent, you are capable of developing yourself as a leader far more than tradition has ever assumed possible. When we liberate the leader in everyone, extraordinary things happen". (Kouzes and Posner 1996, 110)

\section{SUMMARY}

SIA is presented as a key interest-based leadership skill for achieving strategic interests and success. Organizations will face a dynamic and uncertain future in the $21 \mathrm{st}$ century from their external environment, which will be global and highly competitive. SIA will help to achieve an in-depth identification and diagnostic reading of change and stressors facing an organization and its various diverse cross-functional teams.

\section{REFERENCES}

Beckhard, R. and W. Pritchard, 1992. Changing the essence: The art of creating and lading fundamental change in organizations, San Francisco, CA: Jossey-Bass Publishers.

Blanchard, K., 1996. Turning the organizational pyramid upside down, in F. Hesselbin, M. Goldsmith, and R. Beckhard, editors, The leader of the future, San Francisco: Jossey-Bass.

Cox, M. and M. E. Rock 1997. The 7 pillars of visionary leadership, Toronto: Harcourt Brace.

Hesselbein, F., M. Goldsmith, M. and R. Beckhard, 1996. The leaders of the future, San 
Francisco: Jossey-Bass Publishers.

Kouzes, J.M. and B.Z. Posner, 1996. Seven lessons for leading the voyage to the Future, in F. Hesselbin, M. Goldsmith, and R. Beckhard, editors., The leader of the future, San Francisco: Jossey-Bass.

Mintzberg, H., B. Ahlstrand, and J. Campell, 1998. Strategy safari. New York: Free Press.

Pearce, J.A. and R.B. Robinson, 1994. Strategic management, Homewood, ILL.: Irwin.

Pearch, J.A. and R.B. Robinson, 2000. Fomulation, implementation, and control of competitive strategy. New York: Irwin McGraw-Hill. 